\title{
Radioimmunologische Schnellmethode zur Messung von Trijodthyronin im Serum ohne Extraktion
}

\author{
Von P. Hilger'1), J. Herrmann und H. L. KrǗSkemper \\ Aus der 2. Medizinischen Klinik und Poliklinik der Universität Düsseldorf
}

(Eingegangen am 11. Januar/17. März 1973)

Es wird über eine rasche, genaue und empfindliche Methode zur Trijodthyroninbestimmung im Serum ohne vorangehende Extraktion unter Verwendung eines hochspezifischen Antikörpers und 8-Anilinonaphthalin-1-sulfonsäure berichtet.

\section{Rapid radioimmunoassay for the measurement of triiodotbyronine in serum without extraction}

A rapid, precise and highly sensitive method for the determination of triiodthyronine in serum without extraction is described. It is based on the use of a highly specific antibody and 8-anilinonaphthalene-1-sulfonic acid.

Im Laufe des vergangenen Jahres sind einige radioimmunologische Methoden zur Messung der Trijodthyronin-( $\left.\mathrm{T}_{3}\right)$-Konzentration aus Nativserum vorgestellt worden $(1-6,8)$. Diese Verfahren unterscheiden sich erheblich hinsichtlich Empfindlichkeit, Höhe des erforderlichen Antikörpertiters, des Arbeitsaufwandes und der Art der Substanz, die das endogene $T_{3}$ aus seiner Serum-Protein-Bindung freisetzt. Allen gemeinsam sind lange Inkubationszeiten über mehrere Tage. Sie weisen damit relativ geringe Probenkapazitäten pro Arbeitswoche auf, was ihre Anwendbarkeit als klinische Routinemethoden beeintrāchtigt.

Mrrsuna et al. (5) haben kürzlich auf die Möglichkeit hingewiesen, die Gleichgewichtseinstellung der Bindung von markiertem und endogenem $T_{3}$ am Antikörper durch Inkubation bei höheren Temperaturen stark zu beschleunigen. Wir haben dieses Prinzip unter Benutzung von 8-Anilinonaphthalin-1-sulfonsäure als „blockierendes" Agens mit unseren $\mathrm{T}_{3}$-Antikörpern angewandt und gute Erfahrungen gemacht. Die im folgenden dargelegten Ergebnisse lassen erkennen, daß diese Arbeitsmodifikation allen Ansprüchen einer klinisch-chemischen Routinemethode zur $\mathrm{T}_{3}$-Bestimmung genügt.

\section{Material und Methoden \\ Antikörper}

Hochspezifische Antikörper gegen $\mathrm{T}_{3}$ wurden durch Immunisierung von Kaninchen mit an Albumin gekoppeltem $\mathrm{T}_{3}$ (Carbodiimid-Methode (7)) gewonnen; nach 3maliger Booster-Injektion des Antigens (je $1 \mathrm{mg}$ in komplettem Freund's Adjuvans, $0,1 \mathrm{ml}$ an 10 verschiedenen Stellen des Rückens des Kaninchens subkutan injiziert) war der Titer innerhalb von 6 Wochen so hoch, $\mathrm{da} \beta$ das antikörperhaltige Kaninchenserum im Test in einer Endverdünnung von 1:60000 verwendet werden konnte.

\section{Puffer}

0,1 mol/1 Barbital-Puffer pH 8,6, mit Zusatz von $0,1 \mathrm{~g} / 100 \mathrm{ml}$ Rinderserumalbumin.

\section{8-Anilinonapbtbalin-1-sulfonsäure-Lösung}

8-Anilinonaphthalin-1-sulfonsäure (Serva, Heidelberg); 3,22 mmolj 1; gelöst in Barbital-Puffer. Prozentuale Verdrängung von ${ }^{125} \mathrm{~J}-\mathrm{T}_{3}$ vom Thyroxin-bindenden Globulin verschiedener Seren durch 8-Anilinonaphthalin-1-sulfonsāure: $98 \div 2 \%(n=20)$.

\section{Markiertes Trijodtbyronin}

$125 \mathrm{~J}$-L-Trijodthyronin, spezifische Aktivität $80-120 \mathrm{mCi} / \mathrm{mg}$ (Byck Mallinckrodt, Frankfurt) Tracer- $T_{3}-$ Konzentration im Test: $40-60 \mathrm{pg} / 0,1 \mathrm{ml}$ Barbital-Puffer $(60-90 \mathrm{fmol} / 0,1 \mathrm{ml})$.

\section{Eicbleurve}

Nicht-markiertes $\mathrm{T}_{3}$ (Fa. Henning, Berlin) für die Eichkurve wurde in $\mathrm{T}_{3}$-freiem Serum gelöst, so daß Konzentrationen von $10,20,40,100,200 \mathrm{pg} \mathrm{T}$ pro $25 \mu \mathrm{l}$ Serum entstanden $(3,8 ; 7,6$; $15,2 ; 38,2 ; 76,4 \mathrm{fmol} / 25 \mu \mathrm{l})$. Das $T_{3}$-freie Serum wurde durch Adsorption des Hormons an Aktivkohle (160 g/l Serum) hergestellt.

\section{Trenngemiscb}

Nach der Inkubation wird mit Dextran beschichteter Aktivkohle (Norit A) getrennt, dazu werden $1,0 \mathrm{~g}$ Aktivkohle mit $0,1 \mathrm{~g}$ Dextran T 70 (Fa. Pharmacia, Schweden) in $120 \mathrm{ml}$ BarbitalPuffer suspendiert.

Zur Durchführung des Tests wird ein Reagenzgemisch hergestellt, das 2 Teile 8-Anilinonaphthalin-1-sulfonsäure-Lösung und 1 Teil Tracer enthālt. Mit einem Verdünnungsautomaten $\left(F_{a}\right.$. Brand, Wertheim) werden die Proben aufgenommen; $25 \mu \mathrm{l}$ natives Patientenserum werden mit 0,375 ml des Reagenzgemisches aus dem Verdünnungsautomaten in ein Plastikreagenzgefäß $\mathbf{F a}$. Eppendorf, Hamburg) pipettiert. Gleichermaßen wird die Eichkurve pipettiert. Der Test wird mit der Zugabe des Antikörpers gestartet, $0,1 \mathrm{ml}$ 1:12000 verdünntes, Antikörperhaltiges Kaninchenserum in Barbital-Puffer wird mit einer Konstriktionspipette hinzugegeben. Die Proben werden mit einem Mixer etwa $2 \mathrm{~s}$ geschüttelt und für $11 / 2 \mathrm{~h}$ bei $37^{\circ} \mathrm{C}$ inkubiert.

Nach der Inkubation werden die Proben $10 \mathrm{~min}$ lang bei $4^{\circ} \mathrm{C}$ abgekühlt und anschließend mit $0,7 \mathrm{ml}$ kalter Aktivkohlesuspension über waitere $20 \mathrm{~min}$ inkubiert. Nach Zentrifugieren bei $4^{\circ} \mathrm{C}$ über $10 \mathrm{~min} \mathrm{mit} 3000 \mathrm{U} / \mathrm{min}$ (Mistral-Kühlzentrifuge) wird der klare Uberstand abgesaugt und die an der Aktivkohle verbleibende Radioaktivität in einem Gamma-Probenwechsler ( $\mathrm{Fa}$. Philips) gemessen. Bei der Berechnung der gebundenen Impulse pro

1) Mit Unterstützung der Deutschen Forschungsgemeinschaft. 
Minute wird die unspezifische Bindung (U. B.) des Tracers durch die Wandungen der Reaktionsgefäße und durch das Reaktionsgemisch in Abwesenheit des Antikörpers berücksichtigt. Die gebundenen Impulse pro Minute der einzelnen Werte errechnen sich nach der Formel Imp./min bound = Imp./minus - Imp./ min free. Die unspezifische Bindung beträgt je nach Alter der Tracer- $\mathrm{T}_{3}$-Charge zwischen 2 und $10 \%$ der Gesamtradioaktivität im Ansatz.

\section{Ergebnisse und Diskussion}

Die Problematik der radioimmunologischen $T_{3}-B e-$ stimmung aus Patientenserum ohne vorangehende Extraktion liegt neben der Gewinnung eines spezifischen Antikörpers gegen $T_{3}$ darin, eine geeignete Substanz zu finden, die zwar das $T_{3}$ aus seiner Bindung an die Trägerproteine des Serums verdrängt, die Bindung des $\mathrm{T}_{3}$ an den Antikörper jedoch nicht beeinflußt. Von den zahlreichen in der Literatur vorgeschlagenen Substanzen, wie Tetrachlorthyronin, Heparin, Dinitrophenol, Diphenylhydantonin, Thimerosal, NatriumSalicylat und 8-Anilinonaphthalin-1-sulfonsäure werden nur die letzten drei $z$. $Z$. noch bei radioimmunologischen $T_{3}$-Bestimmungen verwandt. Die hier beschriebene Methode, die durch den Einsatz von 8Anilinonaphthalin-1-sulfonsäure, eines sehr guten Antikörpers, kurzer Inkubationszeiten und eines genauen Verdünnungsautomaten gekennzeichnet ist, erscheint als klinische Routinemethode ideal. 150 Proben können an einem Tag von einer Person aufgearbeitet werden, die Ergebnisse können bereits nach $6 \mathrm{~h}$ vorliegen.

Abbildung 1 zeigt eine typische Eichkurve. Gleichzeitig ist eine Kurve aufgetragen, die der Überprüfung der Richtigkeit der Methode dient. Bei Berechnung des B/F Quotienten (gebundene Impulse durch freie Impulse) nach Serienverdünnung eines Hyperthyreoseserums verlief die erhaltene Kurve zur Eichkurve parallel. In Wiederfindungsversuchen nach Zusatz von nicht-markiertem $\mathrm{T}_{3}$ zu einem Hypothyreoseserum war der Korrelationskoeffizient zwischen gemessenen und

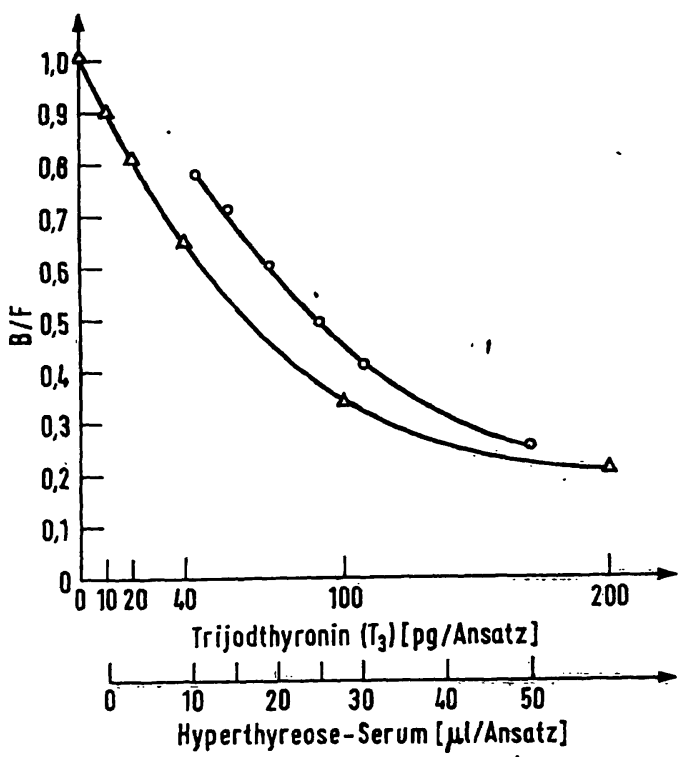

Abb. 1

Standardeichkurve mit $T_{2}-$ Zusatz zu $T_{\mathrm{g}}$ - freiem Serum $(\Delta-\Delta)$. Serumverdünnung von Hyperthyreose-Șerum $(0 \rightarrow 0-0)$

erwarteten Werten mit $r=0,995$ hoch signifikant. Der verwendete $T_{3}$-Antikörper ist für $T_{3}$ hochspezifisch. Die Kreuzreaktion mit $\mathrm{T}_{4}$ war kleiner als $0,2 \%$.

Die untere Empfindlichkeit der Methode entsprechend dem $\mathrm{T}_{3}$-Wert, der sich statistisch gegen $0 \mathrm{pg} \mathrm{T}_{3}$ unterscheiden läßt, liegt bei 5 pg pro Ansatz. Daher können auch Hypothyreoseseren gemessen werden, ohne daß die eingesetzte Serummenge erhöht zu werden braucht. Bei einem $T_{3}$-Gehalt im Patientenserum über $8 \mu \mathrm{g} / \mathrm{l}$ (12 nmol/l) wird eine Verdünnung des Patientenserums notwendig, da die Eichkurve im hohen Meßbereich zu flach wird. Der Variationskoeffizient als Maß der Präzision in Serie betrug $\pm 3,5 \%(n=10)$. Bei der Bestimmung der Präzision von Tag zu Tag $(\mathrm{n}=50)$ betrug der Variationskoeffizient $\pm 10 \%$. Die Materialkosten betragen etwa 0,20 DM pro Bestimmung.

Tab. 1

$\mathrm{T}_{\mathbf{z}}$-Serum-Konzentrationen (ng/l) bei verschiedenen Funktionszuständen der Schilddrüse gemessen mit unterschiedlichen radioimmunologischen Methoden

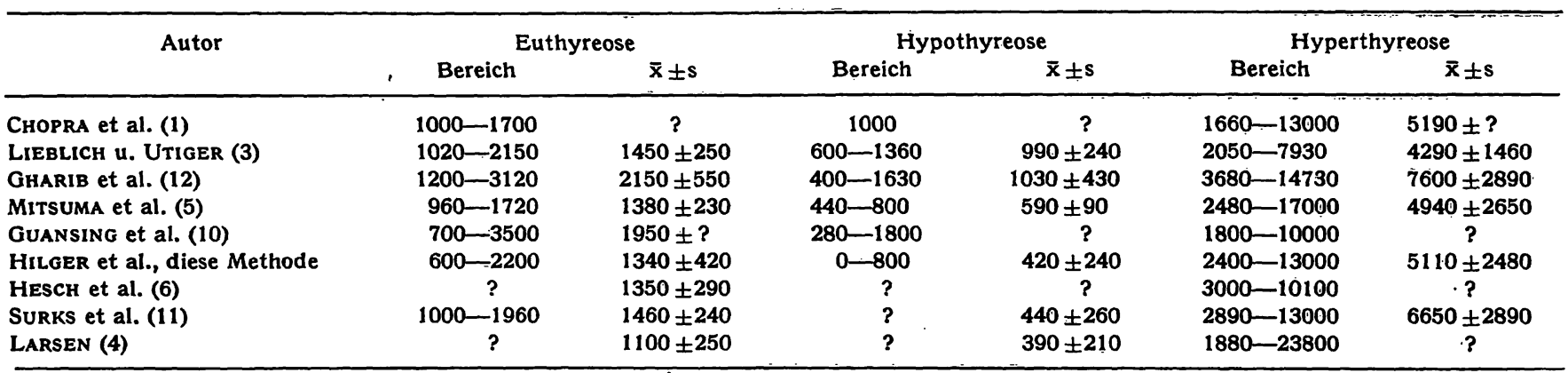

Tab. 2

Mittelwerte und Standardabweichung $(\overline{\mathrm{x}} \pm s)$ von Patientenkollektiven mit verschiedenen Funktionszuständen der Schilddrüse

\begin{tabular}{|c|c|c|c|}
\hline $\begin{array}{l}\text { Euthyreose } \\
\text { Hypothyreose } \\
\text { Hyperthyreose } \\
\text { Alte Patienten } \\
\text { (70_90 Jahre) }\end{array}$ & $\begin{array}{l}n=352 \\
n=31 \\
n=63 \\
n=46\end{array}$ & $\begin{array}{c}1340 \pm 417 \mathrm{ng} / \mathrm{l} \\
424 \pm 239 \mathrm{ng} / \mathrm{l} \\
5110 \pm 2480 \mathrm{ng} / \mathrm{l} \\
664 \pm 403 \mathrm{ng} / \mathrm{l}\end{array}$ & $\begin{array}{l}(2,060 \pm 0,640 \mathrm{nmol} / \mathrm{l}) \\
(0,652 \pm 0,352 \mathrm{nmol} / \mathrm{l}) \\
(7,850 \pm 3,810 \mathrm{nmol} / \mathrm{l}) \\
(1,018 \pm 0,619 \mathrm{nmol} / \mathrm{l})\end{array}$ \\
\hline
\end{tabular}


Die gefundenen Mittelwerte der $T_{3}$-Serumkonzentrationen stimmen gut mit den meisten bisher veröffentlichten, auf kleineren Fallzahlen basierenden Ergebnissen überein (Tab. 1). Mittelwerte und Standardabweichungen sind in Tabelle 2 zusammengefaßt.

Bei Einzelbeobachtungen von $\mathrm{T}_{3}$-Hyperthyreosen (mit normalem Gesamt- $\mathrm{T}_{4}$ und Thyroxin-bindenden Globulin-Gehalt des Serums) fanden wir maximale Werte von $15 \mu \mathrm{g} \mathrm{T} / 1$ (23 nmol/1). Bei $70-90$ jährigen „euthy- reoten" Kliniks-Patienten war der $\mathrm{T}_{3}$-Mittelwert signifikant gegenüber dem anhand eines jüngeren Kollektivs ermittelten Wert gesenkt.

Bei 5 der bisher gemessenen Hypothyreoseseren und in 4 Fällen aus der Gruppe der alten Patienten (trotz normalen oder nur leicht gesenkten Thyroxingehaltes des Serums) lag der $T_{3}$-Serumspiegel unterhalb der Nachweisgrenze (9).

\section{Literatur}

1. Chopra, I. J., Solomon, D. H. \& Beall, G. N. (1971), J. Clin. Invest. 50, 2033-2041. - 2. Mrtsuma, T., Niher, N., GersheGORN, M. C. \& Hollander, C. S. (1971), J. Clin. Invest 50, 2679-2688. - 3. Lieblich, J. \& Utiger, R. D. (1972), J. Clin. Invest. 51, 157-166. - 4. LARSEN, P. R. (1972), J. Clin. Invest. 51, 1939-1949. - 5. Mirsuma, T., Coluccr, J., Shenkman, L. \& Hollander, C. S. (1972), Biochem. Biophys. Res. Commun. 46, 2107-2113. - 6. HESCH, R. D., HürNER, M. \& VON ZUR MÜHLEN, A. (1972), Deut. Med. Wochenschr. 97, 351-353. - 7. Oliver,
G. C., Parker, B. M., Brasfield, D. L. \& Parker, C. W. (1968), J. Clin. Invest. 48, 1035-1042. - 8. LARSEN, P. R. (1971), Metab. Clin. Exp. 20, 976-980. - 9. Herrmann, J., Rusche, J., Hilger, P. \& KRÜSKEMPER, H. L., in Vorbereitung. - 10. GUANSING, A. R., Webster, B. R. \& Hummel, B. W. C. (1971), Clin. Res. 19, 772 (abstract). - 11. SuRKs, M. J., Schadlow, A. R. \& OPPENheIMER, J. H. (1972), J. Clin. Invest. 51, 3104-3113. - 12. Gharib, H., Ryan, R. J., Mayberry, W. E. (1970), J. Clin. Endocr. 31, 709-712.
Priv. Doz. Dr. J. Herrmann

2. Medizinische Klinik der Universität Düsseldorf 4 Düsseldorf

Moorenstraße 5 